\title{
OPEN
}

\section{Quality improvement and practice-based research in neurology using the electronic medical record}

Demetrius M. Maraganore, MD

Roberta Frigerio, MD

Nazia Kazmi, MS

Steven L. Meyers, MD

Meredith Sefa, MS

Shaun A. Walters, MS

Jonathan C. Silverstein, MD, MS

\section{Abstract}

We describe quality improvement and practice-based research using the electronic medical record (EMR) in a community health system-based department of neurology. Our care transformation initiative targets 10 neurologic disorders (brain tumors, epilepsy, migraine, memory disorders, mild traumatic brain injury, multiple

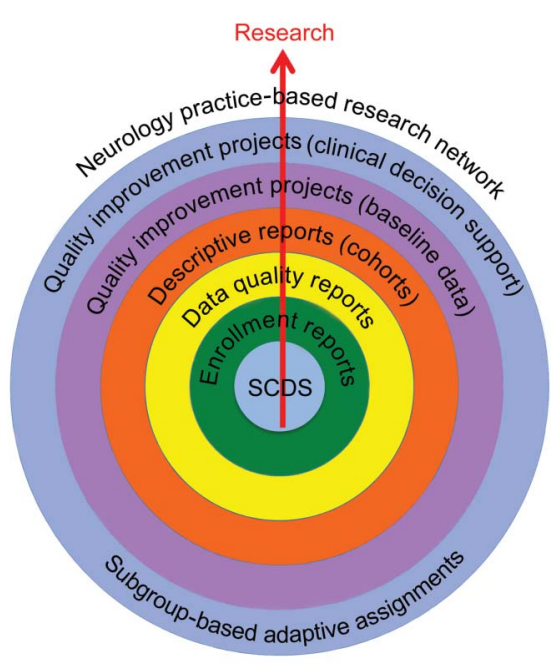

Structure process outcomes sclerosis, neuropathy, Parkinson disease, restless legs syndrome, and stroke) and brain health (risk assessments and interventions to prevent Alzheimer disease and related disorders in targeted populations). Our informatics methods include building and implementing structured clinical documentation support tools in the EMR; electronic data capture; enrollment, data quality, and descriptive reports; quality improvement projects; clinical decision support tools; subgroup-based adaptive assignments and pragmatic trials; and DNA biobanking. We are sharing EMR tools and deidentified data with other departments toward the creation of a Neurology Practice-Based Research Network. We discuss practical points to assist other clinical practices to make quality improvements and practice-based research in neurology using the EMR a reality. Neurol Clin Pract 2015;5:419-429

\footnotetext{
Departments of Neurology (DMM, RF, NK, SLM) and Health Information Technology (MS) and Center for Biomedical Research Informatics (SAW, JCS), NorthShore University HealthSystem, Evanston, IL.

Funding information and disclosures are provided at the end of the article. Full disclosure form information provided by the authors is available with the full text of this article at Neurology.org/cp. The article processing charge was paid from the Research and Development Fund of the Department of Neurology at NorthShore University HealthSystem.

This is an open access article distributed under the terms of the Creative Commons Attribution-NonCommercialNoDerivatives License 4.0 (CC BY-NC-ND), which permits downloading and sharing the work provided it is properly cited. The work cannot be changed in any way or used commercially.
}

Correspondence to: dmaraganore@northshore.org 


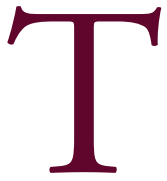

he American Academy of Neurology (AAN) has proposed quality measures, but they have not been incorporated into electronic medical records (EMRs) by vendors. ${ }^{1-5}$ Quality measures documented as unstructured text are not captured discretely, making it difficult to report performance. Neurology is also hampered by a lack of comparative effectiveness research. There are several approved treatments for common neurologic disorders, but it is unknown which are superior in efficacy and tolerability and for which patient subgroups. Traditional clinical trials enroll selected patients, use surrogate measures, follow patients for short periods, and generalize poorly to clinical practice. ${ }^{6-9}$ Data captured in the EMR could be used to identify eligible patients, assign treatments, and measure outcomes at the point of care. ${ }^{10}$

To address these unmet needs, we created a quality improvement and practice-based research initiative in neurology using the EMR. We present a step-by-step description of our quality journey for 10 neurologic disorders (brain tumors, epilepsy, migraine, memory disorders, mild traumatic brain injury [mTBI], multiple sclerosis [MS], neuropathy, Parkinson disease $[\mathrm{PD}]$, restless legs syndrome, and stroke) and for brain health (risk assessments and interventions to prevent Alzheimer disease [AD] in targeted populations).

\section{Overview: A quality journey}

The Department of Neurology at NorthShore University HealthSystem (NorthShore) includes 40 neurologists practicing at 4 hospitals and 8 outpatient sites in the north suburbs of Chicago, IL. The neurologists include generalists and subspecialists in epilepsy, neurodegenerative disorders, MS, neuromuscular disorders, neuro-oncology, sleep disorders, and stroke. Figure 1 illustrates our stepwise process of quality improvement and practice-based research using the EMR. Figure 2 illustrates our progress for 11 projects (10 neurologic disorders plus brain health) as of April 1, 2015.

\section{Step 1: Structured clinical documentation support}

We optimized our EMR (Epic Systems Corporation) by building structured clinical documentation support (SCDS) toolkits that standardize office visits, write progress notes, and capture data. The process of creating the 11 SCDS toolkits (1 per project) is as follows.

Content building We conducted meetings with the neurologists in each program every 2 weeks to select a disorder that is prevalent, variable, and unpredictable and to standardize the content of progress notes (to define the disorder, specify its outcomes using validated measures, and document associated factors). We consulted the medical literature, AAN guidelines, ${ }^{11}$ National Institute of Neurological Diseases and Stroke Common Data Elements, ${ }^{12}$ and subspecialty guidelines. ${ }^{13}$ We envisioned standard workflows (the order and assignment of tasks to a care team that included a medical assistant, sometimes a nurse, and a neurologist) and progress notes (the order and layout in which the content would write). We limited the medical assistant and/or nurse assessments to 15 minutes each and the neurologist assessment to 60 minutes. Content building required 3 months per project.

EMR building We then conducted meetings with programmers from NorthShore's EMR Optimization team every 2 weeks. They built SCDS toolkits that included navigators (a sidebar list of activities assigned to a workflow, with links to electronic forms), electronic forms (modules that included discrete data fields with mouse-click selection of variables represented by radio buttons, tabs, or drop-down menus and additional branching logic, autoscoring, and auto-interpretation features), and summary flow sheets (of prior test results or office visit information). We included optional free text fields (for typing additional comments or narrative history or the impression and plan). The toolkits were designed to support initial and long follow-up visits (conducted annually per our Best Practices, except for malignant brain tumors [every 6 months] and mTBI [at 2 weeks and 3 months]). The toolkits were also designed for optional use at interval visits (e.g., for medication adjustments or review of test results). 


\section{Data captured in the EMR could be used to identify eligible patients, assign treatments, and measure outcomes at the point of care.}

The SCDS toolkits were designed to support clinical practice and research. For example, an electronic pop-up box was built to prompt neurologists to enroll eligible patients in a DNA biobanking initiative. When the neurologist selected enrollment within the pop-up box, an electronic notice was sent to the research team to prompt consenting and blood drawing at the point of care or to document nonparticipation (and why). EMR building required 3 months per project.

Implementation The neurologists tested the SCDS toolkits in the EMR's development environment. Revisions were made and the toolkits were moved to the EMR's production environment. The project team continued to meet every 2 weeks to make revisions based on patient encounters. Implementation required 3 months per project.

In total, SCDS toolkit development required 9 months per project, and we worked on 3 toolkits a year (one undergoing content building, another EMR building, and another implementation at any time). Our toolkits focused on outpatient visits using the EMR's ambulatory environment (except for brain tumors, which used the EMR's hospital outpatient visit environment). As of April 1, 2015, 8 SCDS toolkits have been used several thousand times at routine office visits. Appendix e-1 at Neurology.org/cp provides screenshots of our toolkit for PD.

Figure 1 Our quality journey

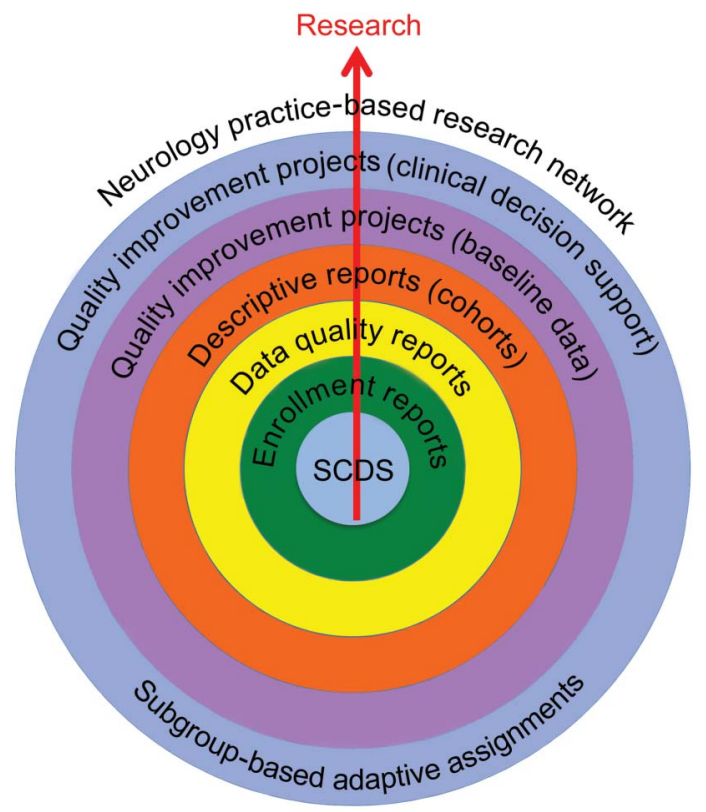

Structure process outcomes

Quality improvement and practice-based research in neurology using the electronic medical record (EMR) consists of a stepwise progression from the development and implementation of structured clinical documentation support (SCDS) toolkits (including note writing and electronic data capture); to enrollment reports; to data quality reports (and data cleaning); to descriptive reports of cohort characteristics; to quality improvement projects (including the creation of benchmark data and quality improvement dashboards); to the use of clinical decision support tools (to hardwire patient safety and improved outcomes); to the use of subgroup-based adaptive assignments (in support of pragmatic clinical trials and personalized medicine); to other research (e.g., biobanking of DNA and the association of genotypes with longitudinal outcomes). The EMR provides a framework for measuring and impacting the 3 dimensions of quality improvement: structure, process, and outcomes. 
Figure 2 Quality stages by disorder

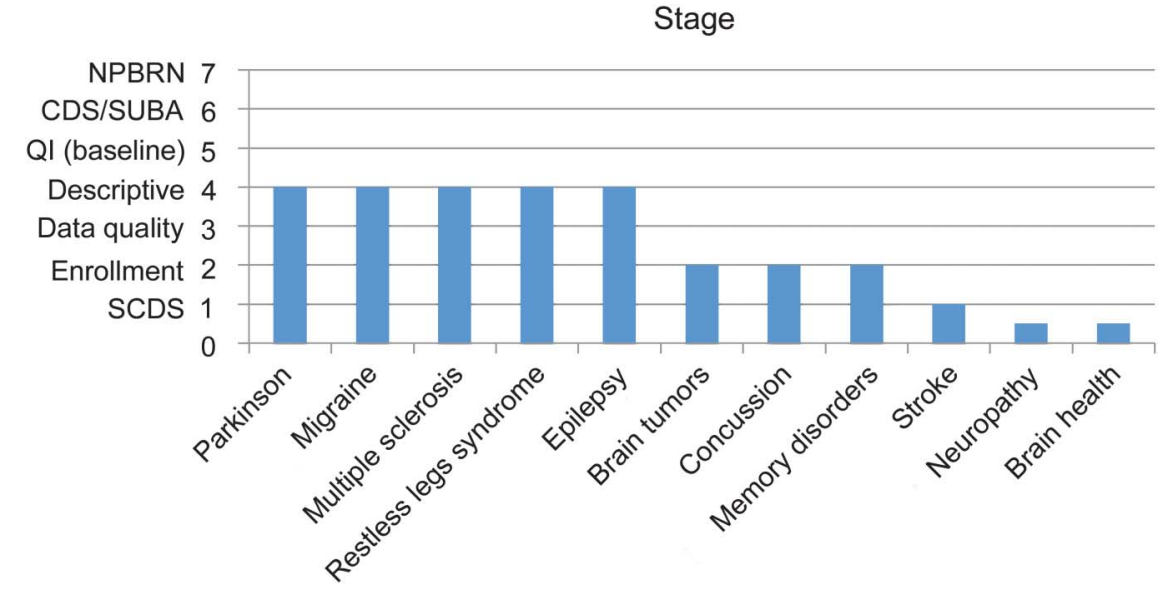

The $\mathrm{x}$-axis lists each of the quality improvement and practice-based research projects in order of implementation at the NorthShore site. The $y$-axis indicates the quality improvement and practice-based research stages. The bars indicate the stage of completion as of April 1, 2015, for each disorder. CDS = clinical decision support; NPBRN = neurology practice-based research network; $\mathrm{QI}=$ quality improvement; SCDS = structured clinical documentation support; SUBA = subgroup-based adaptive assignments.

\section{Step 2: Enrollment reports}

After each SCDS toolkit implementation, neurologists met every 2 weeks with programmers specialized in extracting, transforming, and loading data from the EMR's relational data repository to project-specific data marts in NorthShore's Enterprise Data Warehouse (EDW). The data marts provide an interface for analytic tools. Up to 1,000 fields of data were captured per office visit. Neurologists provided input as to which tasks were required at initial and long follow-up visits and data were binned accordingly.

Within 1 month of project implementation, the EDW programmers created reports to track research enrollment in our DNA biobanking initiative. The enrollment reports are generated monthly. Tables indicate the number of participants by ethnicity and race or by month and year; the number of initial or follow-up visits per year; a listing of enrollees (including dates of consent and initial and follow-up visits, and annotations regarding death, withdrawal from the study, invalid consent, screen failure, or pending blood draw); and a summary of longitudinal follow-up (including numbers of patients actively followed, past due, pending due, or not due; and follow-up rates). Once enrollment reports were produced, project team meetings transitioned to monthly intervals.

\section{Step 3: Data quality reports}

After project-specific data marts were created and enrollment reports were available, the EDW programmers created data quality reports (as early as 3 months after an SCDS toolkit was implemented). These reports indicated which of the required data were missing for each office visit. Data quality reports are distributed to the care team monthly. Data not cleaned within 3 months were archived as permanently missing, and those data were not listed on subsequent reports. The care team learned where they were error prone from the data quality reports, and they remediated their use of the toolkits. When systematic errors occurred for many providers, the teams had the opportunity to improve their use of the toolkits or to request optimizations or a change in data requirements. The monthly reports produced only a few or no data checks per provider once projects were established.

\section{Step 4: Descriptive reports (cohorts)}

Once we enrolled 100 patients into a project and cleaned the data, a statistician created a descriptive report of the cohort. These reports include frequencies, medians, and ranges and bar 


\section{We empowered our neurologists to design the} toolkits, reports, quality improvement projects, and best practice advisories to mitigate "physician burnout."

and box plots for multiple fields of data and score tests (in the sample overall and in strata). These reports are generated quarterly, and by reviewing descriptive data at the cohort level, neurologists identify opportunities for quality improvement. Appendix e- 2 provides a sample descriptive cohort report for migraine.

\section{Step 5: Quality improvement projects and dashboards}

Each neurology team envisioned 3 quality improvement projects using the SCDS toolkits, data, and reports. They developed projects using experience, medical literature searches, and additional Web site resources. ${ }^{11}$ Some quality improvement projects and measures were crosscutting but others were disorder-specific. Table 1 provides a list of quality improvement projects, disorders, and measures. We are analyzing baseline data for the first 100 patients enrolled per disorder and for the first year of follow-up to define quality benchmarks. The neurologists will review quality improvement "dashboards" quarterly.

\section{Next steps}

Clinical decision support We expect to improve quality by standardizing office visits using SCDS toolkits and by regularly reviewing enrollment, data quality, descriptive cohort, and quality improvement dashboard reports. As an added safeguard we are creating electronic pop-up boxes (best practice advisories [BPAs]) that fire at the point of care whenever a quality improvement opportunity is identified, based on data captured by the EMR.

For example, if a patient has PD and the neurologist documents recent falls or a positive pull test and the patient has not seen physical therapy in the past year, upon accepting the note, a BPA will fire and present the mouse-click options "order physical therapy" (which will place the order) or "defer physical therapy" (which will cascade and prompt selection of a reason for deferral). After implementing the BPA, we will track improvements in referral and fall rates vs benchmark data. We empowered our neurologists to design the toolkits, reports, quality improvement projects, and BPAs to mitigate "physician burnout." ${ }^{14,15}$

Subgroup-based adaptive assignments Neurologists will conduct pragmatic trials using the EMR for 10 common neurologic disorders. Table 2 lists the disorders, compared treatments, and outcomes. Our captured data will trigger BPAs prompting reassignment when a "to be compared" treatment is prescribed. For example, a neurologist might prescribe pramipexole to a patient with PD but be prompted to consider ropinirole or rotigotine instead. We will integrate with the EMR subgroup-based adaptive design (SUBA) software that uses data captured from the patients previously enrolled in a given trial to identify subgroup effects and to assign patients newly enrolled in the trial to treatments that are expected to be more effective in real time. ${ }^{16}$ The statistical features of SUBA include the continuous learning of patient subgroups based on a random partition model and the adaptive allocation of patients to the best treatment based on posterior predictive probabilities. ${ }^{17-24}$ SUBA has desirable performance in computer-simulated trials with a sample size of 300 .

Neurology practice-based research network We created a neurology practice-based research network (NPBRN) using the EMR. We are sharing SCDS toolkits and data for quality 
Table 1 Examples of quality improvement projects using the electronic medical record

\begin{tabular}{ll} 
Quality initiatives & Disorders \\
$\begin{array}{l}\text { Detect and manage } \\
\text { psychosocial stress }\end{array}$ & Brain tumors, epilepsy \\
$\begin{array}{l}\text { Detect and manage } \\
\text { depression or anxiety }\end{array}$ & $\begin{array}{l}\text { Brain tumors, epilepsy, migraine, } \mathrm{MCl}, \mathrm{mTBI}, \\
\text { MS, neuropathy, PD, RLS }\end{array}$ \\
$\begin{array}{l}\text { Detect and manage cognitive } \\
\text { impairment }\end{array}$ & Brain tumors, epilepsy, $\mathrm{MCl}, \mathrm{MS}, \mathrm{PD}$, stroke \\
\hline
\end{tabular}

Prevent fall-related injury

Detect and manage
osteoporosis
Prevent teratogenesis
$\begin{aligned} & \text { Detect and manage sleep } \\ & \text { disorder }\end{aligned}$

$\begin{array}{ll}\text { Detect temporal arteritis } & \text { Migraine } \\ \text { Protect vulnerable adults } & \mathrm{MCl}\end{array}$

Prevent motor vehicle $\quad \mathrm{MCl}$, neuropathy, $\mathrm{PD}$ accidents

Prevent complications of immunotherapy

$\begin{array}{ll}\text { Detect Wilson disease } & \text { PD } \\ \begin{array}{l}\text { Detect and manage } \\ \text { compulsive disorder }\end{array} & \text { PD, RLS } \\ \text { Detect iron deficiency } & \text { RLS }\end{array}$

Brain tumors, epilepsy

Brain tumors, epilepsy

MS, neuropathy

\section{Quality measurements}

If NCCN or QOLIE-10 score positive, frequency of social worker referral order

If CES-D, GAD-7, GDS, or NDDI-E score positive, frequency of antidepressant or anxiolytic medication order and/or psychiatry referral order

If MoCA test score positive, frequency of neuropsychological testing order or documentation of advance care planning

Brain tumors, MCl, MS, neuropathy, PD, stroke If falls in the past year or Hoehn and Yahr stage 3+ (PD), frequency of physical therapy order

If on enzyme-inducing anticonvulsant, frequency of bone density test order

If woman of childbearing age on anticonvulsant, frequency of folate medication order

If ESS or ISI screen positive, frequency of sleep study order

If age $>55 y$ and headache less than $1 y$, frequency of ESR and/or CRP order

If FAQ reveals difficulty with financial management, frequency of social worker order

If driving safety screen positive, frequency of driving evaluation order

If steroids or disease-modifying therapies are prescribed, frequency of orders (CBC, CMP, TSH, pregnancy test, VZV antibody, JCV index, urinalysis, EKG, ophthalmology)

If symptom onset <age $55 \mathrm{y}$, frequency of ceruloplasmin order

If compulsive disorder screens positive, frequency of discontinuation of dopamine agonist orders

If no ferritin or anemia testing in past year, frequency of iron, total iron binding capacity, ferritin, CBC order

Abbreviations: $\mathrm{CBC}=$ complete blood count; CES-D = Center for Epidemiologic Studies Depression ${ }^{\mathrm{e}} ; \mathrm{CMP}^{\mathrm{C}}=\mathrm{comprehensive}$ metabolic panel; $\mathrm{CRP}=$ C-reactive protein; ESR = erythrocyte sedimentation rate; ESS = Epworth Sleepiness Scale ${ }^{e 2}$; FAQ $=$ Functional Activities Questionnaire ${ }^{\mathrm{e}} ; \mathrm{GAD}-7=$ Generalized Anxiety Disorder 7-item ${ }^{\mathrm{e}}$; GDS = Geriatric Depression Scale ${ }^{\mathrm{5}}$; ISI = Insomnia Severity Index ${ }^{6}$; JCV = John Cunningham virus; $\mathrm{MCl}=$ mild cognitive impairment; MoCA = Montreal Cognitive Assessment $^{\mathrm{e}}$; $\mathrm{MS}=$ multiple sclerosis; $\mathrm{mTBI}=$ mild traumatic brain injury; $\mathrm{NCCN}=$ National Comprehensive Cancer Network Distress Thermometere8; NDDI-E = Neurological Disorders Depression Inventory for Epilepsy ${ }^{\mathrm{e}}$; PD = Parkinson disease; QOLIE-10 = Quality of Life in Epilepsy-10 ${ }^{\mathrm{e} 10}$; RLS = restless legs syndrome; TSH = thyroid-stimulating hormone; VZV = varicella-zoster virus.

See appendix e-3 for e-references.

improvement and practice-based research. We obtained a list of Epic clients and invited neurology practices to join the NPBRN. The AAN is providing guidance regarding integration of quality measures into the EMR and assisting with recruitment of sites and dissemination of findings. Details are as follows (see also appendix e-4).

A. Sharing of SCDS toolkits. NorthShore is sharing its toolkits for 10 neurologic disorders with the other neurologists under a free license sharing agreement. Sharing of tools will be achieved via the EMR's application exchange. This will substantially reduce the work of installing toolkits from one health system to another. 
Table 2 Examples of pragmatic trials using the electronic medical record

\begin{tabular}{|c|c|}
\hline Disorder & Compared treatments \\
\hline $\begin{array}{l}\text { Brain tumors } \\
\text { (seizures) }\end{array}$ & Lamotrigine, levetiracetam, valproic acid \\
\hline $\begin{array}{l}\text { Epilepsy (other } \\
\text { seizures) }\end{array}$ & Lamotrigine, levetiracetam, valproic acid \\
\hline $\mathrm{MCl}$ & Donepezil (hs), rivastigmine patch, Namenda XR \\
\hline
\end{tabular}

Migraine

(prophylaxis)

Migraine (abortive)

MS

Acthar (SQ), methylprednisolone (IV), crossover
(relapses)

Neuropathy (painful) Duloxetine (am), pregabalin (bid), amitryptiline (hs)

PD

Pramipexole $E R$, ropinirole $X L$, rotigotine patch

RLS

Pramipexole (hs), ropinirole (hs), rotigotine patch

Stroke

Aspirin, clopidogrel, clopidogrel (CYP2C19)

\section{Outcome measures}

Survival (free of discontinuation, adjunctive therapy, seizures, hospice, death); $50 \%$ reduction of seizure frequency; $\triangle$ CES-D, GAD-7, KPS, MDASI, MoCA, NCCN

Survival (free of discontinuation, adjunctive therapy, seizures, death); $50 \%$ reduction of seizure frequency; $\Delta$ ESS, GAD-7, MoCA, NDDI-E, QOLIE-10

Survival (free of discontinuation, adjunctive therapy, dementia); $\triangle \mathrm{FAQ}, \mathrm{GDS}, \mathrm{MoCA}$

Survival (free of discontinuation, adjunctive therapy, medication overuse, chronic transformation); 50\% reduction of migraine frequency; $\Delta$ CES-D, GAD-7, ISI, MIDAS, MSQ

Survival (free of discontinuation, adjunctive therapy, medication overuse, chronic transformation); 2 hours pain relief; 2 hours and 24 hours pain free; $\Delta$ CES-D, GAD-7, ISI, MIDAS, MSQ

Survival (free of discontinuation, adjunctive therapy); RPCQ/Symptom Inventory (2 wk, 3 mo); $\Delta$ CES-D, GAD7, ISI (3 mo)

Survival (free of discontinuation, adjunctive therapy, relapse, disease progression); $\Delta$ 9-hole peg, 25-ft walk, CES-D, EDSS, FSS, GAD-7, MoCA

Survival (free of discontinuation, adjunctive therapy); $\Delta$ CES-D, EQ-5D, Neuropathic Pain Scale

Survival (free of discontinuation, adjunctive therapy, levodopa, dyskinesias, motor fluctuations, freezing, falls, nursing home, death); $\Delta$ 9-hole peg, ESS, GDS, MoCA, UPDRS 1-6

Survival (free of discontinuation, adjunctive therapy, augmentation, impulse control); $\triangle$ CES-D, ESS, GAD-7, IRLSSG, ISI, PSQI

Survival (free of discontinuation, adjunctive therapy, TIA, ischemic stroke, intracranial hemorrhage, systemic hemorrhage, myocardial infarction, cancer, nursing home, death); $\Delta$ Barthel index, MoCA, mRankin, NIHSS

Abbreviations: CES-D = Center for Epidemiologic Studies Depression; EDSS = Expanded Disability Status Scale ${ }^{\mathrm{e} 11}$; EQ-5D = EuroQol 5-De12; ESS = Epworth Sleepiness Scale; FAQ = Functional Activities Questionnaire; FSS = Functional Symptom Score ${ }^{\mathrm{e} 13}$; GAD-7 = Generalized Anxiety Disorder 7-item; GDS = Geriatric Depression Scale; IRLSSG = International Restless Legs Syndrome Study Group Severity Scale ${ }^{14}$; ISI = Insomnia Severity Index; KPS = Karnofsky Performance Scale; $\mathrm{MCI}=$ mild cognitive impairment; MDASI = MD Anderson Symptom Inventorye15; MIDAS = Migraine Disability Assessmente16; MoCA = Montreal Cognitive Assessment; mRankin = modified Rankin Scalee17; MS = multiple sclerosis; MSQ = Migraine-Specific Quality-of-Life Questionnaire ${ }^{18} ; \mathrm{mTBI}=$ mild traumatic brain injury; NCCN = National Comprehensive Cancer Network Distress Thermometer; NDDI-E = Neurological Disorders Depression Inventory for Epilepsy; NIHSS = NIH Stroke Scale ${ }^{19}$; PD = Parkinson disease; PSQI = Pittsburgh Sleep Quality Indexe20; QOLIE-10 = Quality of Life in Epilepsy-10; RLS = restless legs syndrome; RPCQ = Rivermead Post-Concussion Symptoms Questionnaire ${ }^{e 21}$; UPDRS = Unified Parkinson's Disease Rating Scale..$^{\text {e22 }}$

See appendix e-3 for e-references.

B. Sharing of deidentified data. The neurologists will share deidentified data captured by the SCDS toolkits (minus protected health information). The NPBRN will govern the use of the shared data collaboratively. We expect no overlapping patients (1 site per state).

C. Data management. NorthShore will manage the data in collaboration with other NPBRN sites. Data submitted to the EDW will be the object of constant monitoring. We will provide monthly encounter (akin to enrollment) reports and data quality reports, and quarterly descriptive cohort and quality improvement dashboard reports to participating neurologists. 
D. Analyses of the data. For each quality improvement initiative (table 1), we will describe the baseline demographic and clinical characteristics for the patients by site and combined. Several statistical packages interface with the EDW and will be used for comparisons. Neurologists are expected to assess thousands of unique patients per year at each NPBRN site separately and tens of thousands of new and established patients per year combined. We have registered the NPBRN (8 sites presently). ${ }^{25}$

Biobanking and research informatics initiative A driver of our quality journey at NorthShore has been our department's biobanking and research informatics initiative. Neurologists are enrolling 1,000 patients in each of 11 SCDS cohorts. Following informed consent and with institutional review board approval, enrollees provide a blood sample for DNA and plasma storage and permission to associate information in their blood with information in their medical records. We will use this resource for molecular prognostic studies. Appendix e5 summarizes biobanking as of April 1, 2015.

\section{Practical points}

From the point of view of practicing neurologists, our use of the EMR may seem futuristic. Many neurologists do not use an EMR or have limited capabilities for its optimization or data sharing. Nevertheless, we conclude by addressing many practical points to assist other clinical practices in making quality improvements and practice-based research using the EMR a reality.

How to promote buy-in Physicians and staff may resist the implementation of SCDS toolkits and related clinical workflows. To build buy-in we regularly communicated benefits of SCDS, including (1) care navigation, (2) note writing, (3) timely communications, (4) value-based payment, (5) patient safety, (6) quality improvement, (7) comparative effectiveness, (8) personalized medicine, (9) scholarly activities, and (10) innovation. We engaged the neurologists in the design, building, and implementation of toolkits and the related reports and quality improvement initiatives and met regularly to improve tools and processes. We incorporated bonuses for group performance in quality goals into our compensation model. In other practices the data captured might also be used to meet federal quality reporting mandates such as the Physician Quality Reporting System. ${ }^{26,27}$

Our objective was to stay "time neutral." We encouraged neurologists to pilot test the SCDS toolkits in the EMR development environment and we placed frequent requests for optimizations post implementation. Our new office visits and long follow-up visits are 60 minutes each (neurologist component) and we support our neurologists with medical assistants or sometimes nurses, but the time and resources allocated can easily be reduced because of the modular build of our toolkits. Other neurology practices may choose to designate some toolkits (navigators) or modules (electronic forms) as required and others as optional or to implement neurology office visit workflows including students, residents, fellows, physician assistants, or advanced practice nurses (in addition to or instead of medical assistants and nurses).

We also anticipate challenges to the conduct of practice-based research, such as pragmatic trials, using the EMR. ${ }^{28}$ Neurologists or patients may find it cumbersome to engage in research at the point of care. Ethicists determined that pragmatic trials comparing standard therapies via the EMR with no additional burden or risk to patients might be exempted from informed consent. ${ }^{29}$ Alternatively, the burden of informed consent can be reduced by using electronic consent forms. Consenting electronically at the point of care is standard practice for risk-bearing clinical procedures at some institutions, and others have reported a favorable experience with electronic consenting for research. ${ }^{30,31}$

How to promote collaboration We are licensing the use of our SCDS toolkits to other neurology practices at no direct cost, provided they are willing to join the NPBRN and share deidentified data. The installation costs for the toolkits will be nominal compared with the installation costs of the EMR (and a fraction of the cost of building toolkits from scratch). Practices that use EMRs are accustomed to some annual cost associated with upgrades. All of the 
NPBRN principal investigators are department leaders, and we will regularly discuss engagement tactics. We will accommodate shorter office visits at some sites by designating a minimal set of SCDS toolkits or modules as required and others as recommended. We are exploring workflows in which patients may self-enter some information into the electronic forms using an online portal or computer kiosks or tablet computers at check-in to accommodate clinical practices with limited staff support. We will empower neurologists at each NPBRN site to propose changes to the toolkits and to have access to data. We will provide reports at the patient encounter (rather than research enrollment) level. NorthShore will leverage its experience in the conduct of EMR-based data sharing in a consortium. ${ }^{32}$

We also hope that EMR vendors will incorporate SCDS toolkits similar to ours and make them broadly available to clients as part of their standard products. Once common data elements are extracted, transformed, and loaded into a data warehouse (regardless of the EMR platform), the same enrollment/encounter, descriptive, and quality reports can be used and the quality improvement initiatives can be the same. The AAN is creating a registry (the Axon Registry) to demonstrate the quality and value of neurologic care, to support improvements to care, and to alleviate the administrative burdens of quality reporting for payment and maintenance of certification. ${ }^{33}$ Data captured using SCDS toolkits such as ours can be easily exported to the AAN registry, forgoing the need for extraction software, natural language processing, or chart abstraction.

\section{REFERENCES}

1. Cheng EM, Tonn S, Swain-Eng R, Factor SA, Weiner WJ, Bever CT Jr; American Academy of Neurology Parkinson Disease Measure Development Panel. Quality improvement in neurology: AAN Parkinson disease quality measures: report of the Quality Measurement and Reporting Subcommittee of the American Academy of Neurology. Neurology 2010;75:2021-2027.

2. Fountain NB, Van Ness PC, Swain-Eng R, Tonn S, Bever CT Jr; American Academy of Neurology Epilepsy Measure Development Panel and the American Medical Association-Convened Physician Consortium for Performance Improvement Independent Measure Development Process. Quality improvement in neurology: AAN epilepsy quality measures: Report of the Quality Measurement and Reporting Subcommittee of the American Academy of Neurology. Neurology 2011; 76:94-99.

3. Odenheimer G, Borson S, Sanders AE, et al. Quality improvement in neurology: dementia management quality measures. Neurology 2013;81:1545-1549.

4. Miller RG, Brooks BR, Swain-Eng RJ, et al. Quality improvement in neurology: amyotrophic lateral sclerosis quality measures: report of the quality measurement and reporting subcommittee of the American Academy of Neurology. Neurology 2013;81:2136-2140.

5. England JD, Franklin G, Gjorvad G, et al. Quality improvement in neurology: distal symmetric polyneuropathy quality measures. Neurology 2014;82:1745-1748.

6. Chalkidou K, Tunis S, Whicher D, Fowler R, Zwarenstein M. The role for pragmatic randomized controlled trials (pRCTs) in comparative effectiveness research. Clin Trials 2012;9:436-446.

7. Patsopoulos NA. A pragmatic view on pragmatic trials. Dialogues Clin Neurosci 2011;3:217-224.

8. Tunis SR, Stryer DB, Clancy CM. Practical clinical trials: increasing the value of clinical research for decision making in clinical and health policy. JAMA 2003;290:1624-1632.

9. Vickers AJ, Scardino PT. The clinically-integrated randomized trial: proposed novel method for conducting large trials at low cost. Trials 2009;10:14.

10. Staa TP, Goldacre B, Gulliford M, et al. Pragmatic randomised trials using routine electronic health records: putting them to the test. BMJ 2012;344:e55.

11. American Academy of Neurology. Guidelines and Quality Measures. Available at: https://www.aan. com/Guidelines/ and https:/www.aan.com/practice/quality-measures/. Accessed March 1, 2015.

12. National Institute of Neurological Disorders and Stroke. Common Data Elements. Available at: http://www.commondataelements.ninds.nih.gov/. Accessed January 20, 2015.

13. American Heart Association. Get With The Guidelines. Available at: http://www.heart.org/ HEARTORG/HealthcareResearch/GetWithTheGuidelines/Get-With-The-Guidelines-Stroke_UCM_ 306098_SubHomePage.jsp. Accessed January 20, 2015.

14. Bernat JL. Challenges to ethics and professionalism facing the contemporary neurologist. Neurology 2014;83:1285-1293.

15. Sigsbee B, Bernat JL. Physician burnout: a neurologic crisis. Neurology 2014;83:2302-2306. 
16. Xu Y, Trippa L, Müller P, Ji Y. Subgroup-based adaptive (SUBA) designs for multi-arm biomarker trials. Stat Biosci; doi: 10.1007/s12561-014-9117-1. Epub 2014 July 17.

17. Cai C, Yuan Y, Ji Y. A Bayesian dose-finding design for oncology clinical trials of combinational biological agents. J R Stat Soc Ser C Appl Stat 2014;63:159-173.

18. Hu B, Ji Y, Tsui KW. Bayesian estimation of inverse dose response. Biometrics 2008;64:1223-1230.

19. $\mathrm{Hu} \mathrm{B}$, Bekele BN, Ji Y. Adaptive dose insertion in early phase clinical trials. Clin Trials 2013;10: 216-224.

20. Ji Y, Bekele BN. Adaptive randomization for multiarm comparative clinical trials based on joint efficacy/toxicity outcomes. Biometrics 2009;65:876-884.

21. Ji Y, Wang SJ. Modified toxicity probability interval design: a safer and more reliable method than the 3 + 3 design for practical phase I trials. J Clin Oncol 2013;31:1785-1791.

22. Pan H, Xie F, Liu P, Xia J, Ji Y. A phase I/II seamless dose escalation/expansion with adaptive randomization scheme (SEARS). Clin Trials 2014;11:49-59.

23. Xie F, Ji Y, Tremmel LA Bayesian adaptive design for multi-dose, randomized, placebo-controlled phase I/II trials. Contemp Clin Trials 2012;33:739-748.

24. Yin G, Li Y, Ji Y. Bayesian dose-finding in phase I/II clinical trials using toxicity and efficacy odds ratios. Biometrics 2006;62:777-784.

25. Agency for Healthcare Research and Quality. Practice-Based Research Networks. Available at: http:// pbrn.ahrq.gov/pbrn-registry/neurology-practice-based-research-network. Accessed April 3, 2015.

26. Centers for Medicare \& Medicaid Services. Physician Quality Reporting System. Available at: http://www. cms.gov/Medicare/Quality-Initiatives-Patient-Assessment-Instruments/PQRS/. Accessed May 16, 2015.

27. American Academy of Neurology. Physician Quality Reporting System. Available at: https://www.aan. com/go/practice/pay/pqrs. Accessed May 16, 2015.

28. van Staa TP, Dyson L, McCann G, et al. The opportunities and challenges of pragmatic point-of-care randomised trials using routinely collected electronic records: evaluations of two exemplar trials. Health Technol Assess 2014;18:1-146.

29. Faden R, Kass N, Whicher D, Stewart W, Tunis S. Ethics and informed consent for comparative effectiveness research with prospective electronic clinical data. Med Care 2013;51:S53-S57.

30. Chalil Madathil K, Koikkara R, Obeid J, et al. An investigation of the efficacy of electronic consenting interfaces of research permissions management system in a hospital setting. Int J Med Inform 2013; 82:854-863.

31. Issa MM, Setzer E, Charaf C, et al. Informed versus uninformed consent for prostate surgery: the value of electronic consents. J Urol 2006;176:694-699.

32. Kho AN, Hynes DM, Goel S, et al; CAPriCORN Team. CAPriCORN: Chicago Area PatientCentered Outcomes Research Network. J Am Med Inform Assoc 2014;21:607-611.

33. American Academy of Neurology. Axon Registry. Available at: https://www.aan.com/practice/axonregistry/. Accessed April 3, 2015.

\section{ACKNOWLEDGMENT}

The authors acknowledge the generous funding support of the Auxiliary of NorthShore University HealthSystem and thank the medical assistants, nurses, neurologists, EMR Optimization and Enterprise Data Warehouse programmers, administrators, and research personnel at NorthShore University HealthSystem who contributed to the quality improvement and practice-based research initiative using the EMR. The authors thank Vimal Patel, PhD for his assistance with editing, formatting, and submitting the manuscript for publication. We also thank the principal investigators of the neurology practice-based research network and Becky Schierman, MPH and Dr. Timothy Pedley of the American Academy of Neurology for their collaboration. Finally, the authors thank the neurology patients who inspire us to improve quality and to innovate our clinical practice.

\section{AUTHOR CONTRIBUTIONS}

Demetrius M. Maraganore: drafting/revising the manuscript, study concept or design, analysis or interpretation of data, acquisition of data, statistical analysis, study supervision, obtaining funding. Roberta Frigerio: drafting/revising the manuscript, analysis or interpretation of data, acquisition of data, study supervision. Nazia Kazmi: drafting/revising the manuscript, acquisition of data, study supervision. Steven L. Meyers: drafting/revising the manuscript, analysis or interpretation of data, acquisition of data, study supervision. Meredith Sefa: drafting/revising the manuscript. Shaun A. Walters: analysis or interpretation of data, acquisition of data, statistical analysis. Jonathan C. Silverstein: drafting/revising the manuscript, study concept or design, acquisition of data, study supervision. 


\section{STUDY FUNDING}

Targeted study funding is provided by the Agency for Healthcare Research and Quality grant 1R01HS024057-01 "Quality Improvement and Practice Based Research in Neurology Using the EMR," awarded to D.M.M. on June 30, 2015 (after this paper was accepted for publication).

\section{DISCLOSURES}

D.M. Maraganore has received philanthropic support from the Auxiliary of NorthShore University HealthSystem; serves on the editorial board of Parkinsonism and Related Disorders; is an author on 2 pending patents: (1) method to treat Parkinson's disease and (2) method to predict Parkinson's disease; and receives research support from GE Healthcare and the Agency for Health Care Research and Quality (1R01HS024057-01). R. Frigerio's spouse has received philanthropic support from the Auxiliary of NorthShore University HealthSystem; serves on the editorial board of Parkinsonism and Related Disorders; is an author on 2 pending patents: (1) method to treat Parkinson's disease and (2) method to predict Parkinson's disease; and receives research support from GE Healthcare and the Agency for Health Care Research and Quality (1R01HS024057-01). N. Kazmi is employed as a Clinical Research Associate at Cepheid and serves as a consultant for Nutrabiotix, LLC. S.L. Meyers and M. Sefa report no disclosures. S.A. Walters is employed as Senior Programmer/Analyst at NorthShore University Health System. J.C. Silverstein serves on a scientific advisory board for Western Governors University Health Professions Council; is cofounder of Computationdoc LLC; receives research support from Baxter, a Patient-Centered Outcomes Research Institute subgrant from Chicago Community Trust CDRN CAPriCORN, and a Centers for Medicare and Medicaid Services subgrant from University of Chicago; and is President and CEO of the Joseph H. Kanter Foundation, a 501c3 doing health care research (salary support to NorthShore as release time). Full disclosure form information provided by the authors is available with the full text of this article at Neurology.org/cp.

\section{Related articles from AAN physician and patient resources}

\section{Neurology ${ }^{\circledR}$ Clinical Practice}

Special requirements for electronic medical records in neurology February 2015;5:67-73.

Practical steps for implementing quality measurement in practice October 2014;4:447-453.

\section{Neurology ${ }^{\circledR} \quad-\quad$ Neurology.org}

Ethical and quality pitfalls in electronic health records March 12, 2013;80:1057-1061.

\section{Neurology Today ${ }^{\circledR}$ - Neurotodayonline.com}

BOOKSHELF: The Promise and Peril of Wired Medicine July 16, 2015;15:22-23.

IN PRACTICE: Clinical Informatics: A Nascent Subspecialty Gains Momentum - And Neurologists Are in the Mix June 18, 2015;15:18-19. 


\title{
Neurology ${ }^{\circ}$ Clinical Practice
}

\author{
Quality improvement and practice-based research in neurology using the electronic \\ medical record \\ Demetrius M. Maraganore, Roberta Frigerio, Nazia Kazmi, et al. \\ Neurol Clin Pract 2015;5;419-429 Published Online before print September 24, 2015 \\ DOI 10.1212/CPJ.0000000000000176
}

This information is current as of September 24, 2015

$\begin{array}{ll}\begin{array}{l}\text { Updated Information \& } \\ \text { Services }\end{array} & \begin{array}{l}\text { including high resolution figures, can be found at: } \\ \text { http://cp.neurology.org/content/5/5/419.full.html }\end{array} \\ \text { Supplementary Material } & \begin{array}{l}\text { Supplementary material can be found at: } \\ \text { http://cp.neurology.org/content/suppl/2015/09/24/CPJ.0000 }\end{array} \\ \text { 176.DC1 } & \text { This article cites } 25 \text { articles, } 2 \text { of which you can access for } \\ \text { http://cp.neurology.org/content/5/5/419.full.html\#\#ref-lis } & \text { This article has been cited by } 5 \text { HighWire-hosted articles } \\ \text { http://cp.neurology.org/content/5/5/419.full.html\#\#othera } & \text { Information about reproducing this article in parts (figure } \\ \text { Citations } & \text { its entirety can be found online at: } \\ \text { http://cp.neurology.org/misc/about.xhtml\#permissions } & \text { Information about ordering reprints can be found online: } \\ \text { Permissions \& Licensing } & \text { http://cp.neurology.org/misc/addir.xhtml\#reprintsus }\end{array}$

Updated Information \&

http://cp.neurology.org/misc/addir.xhtml\#reprintsus

Neurol Clin Pract is an official journal of the American Academy of Neurology. Published continuously since 2011, it is now a bimonthly with 6 issues per year. Copyright $(92015$ American Academy of Neurology. All rights reserved. Print ISSN: 2163-0402. Online ISSN: 2163-0933.

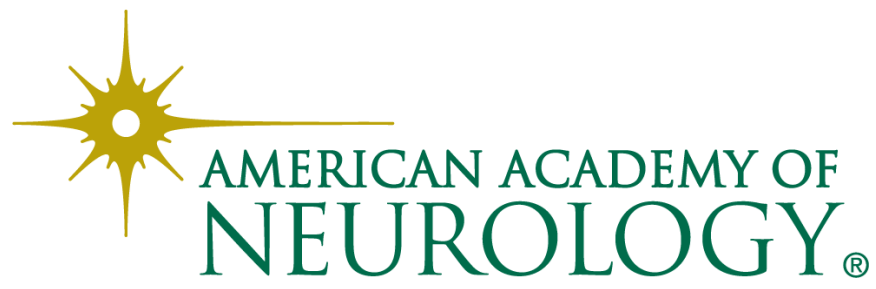

